\title{
Evaluation of a Rumen Protected Omega 3 Supplement for Reproduction in Dairy Cows as Determined in Three Large Herd Field Trials
}

\author{
Malcolm Ballard ${ }^{*}$, Anthony T. Byrd ${ }^{2}$ \\ ${ }^{1}$ The Ballard Group, Inc. 6075 Miami Rd., Cincinnati, OH, USA \\ ${ }^{2}$ Anthony T. Byrd ATB Specialty Products, Inc. 5813 Greencrest Drive, Hamilton, OH, USA \\ Email: *malcolm.ballard@tbgnutrition.com, atbyrd@fuse.net
}

How to cite this paper: Ballard, M. and Byrd, A.T. (2018) Evaluation of a Rumen Protected Omega 3 Supplement for Reproduction in Dairy Cows as Determined in Three Large Herd Field Trials. Open Journal of Animal Sciences, 8, 346-355.

https://doi.org/10.4236/ojas.2018.83026

Received: July 2, 2018

Accepted: July 24, 2018

Published: July 27, 2018

Copyright (c) 2018 by authors and Scientific Research Publishing Inc. This work is licensed under the Creative Commons Attribution International License (CC BY 4.0).

http://creativecommons.org/licenses/by/4.0/

\begin{abstract}
Omega 3 fatty acids have been shown to support reproductive performance in dairy cows, but large amounts are needed due to ruminal biohydrogenation of fatty acids. Three long-term large herd feeding trials, two with heifers and one with mature cows, were conducted to evaluate the effects of adding a rumen protected fish oil supplement on reproduction. In all trials, there were over 1000 animals eligible to be bred/treatment. Cows received a ration with $40 \mathrm{~g}$ of a rumen protected fish oil supplement (Salmate ${ }^{\circledR}$ the Ballard Group, Cincinnati Ohio) during the test periods, while controls received no supplementation. The additive was provided to the test cows from the onset of lactation until $90 \pm 5$ days in milk. Cows entering the pen on or after the first day of the study were included in the dataset. Individual cow records were compiled by Dairy Herd Improvement Association (National DHIA, Verona WI USA) were compared to records from the same time period the year prior. Results were compared using ANOVA for single mean variables and Fisher's exact test for proportional data. In trials 1 and 2 involving heifers, pregnancy rates were improved $(22.4 \%$ vs $14.8 \%$ in trial 1 and 22.0 vs $17.8 \%$ in trial $2,(p<$ $0.05)$ ). In both cases the improved pregnancy rate could be attributed to higher numbers of cattle bred that became pregnant $(P<0.05)$, resulting in fewer services/conception $(P<0.05)$. Early embryonic abortion rates were under $2 \%$ in trial 1 and did not differ by treatment. Embryonic abortions rates were 9.2\% for the control group as compared to $5.6 \%$ for the test group in trial 2, but failed to reach significance. There were no differences in pregnancy rates for the mature cows evaluated in trial $3(P>0.05)$. However, early embryonic abortion rates were 16.8 during the control period, as compared to $4.7 \%$ during the test feeding period. The rumen protected omega 3 fatty acid supplement was found to be of benefit to reproductive performance in dairy cows.
\end{abstract}


The supplement may improve the percentage of cattle bred that become pregnant in herds where this metric is low. Early term abortions may be lowered, particularly in herds where this is high.

\section{Keywords}

Encapsulation, Omega-3, Dairy Cow Reproduction

\section{Introduction}

The cornerstone of successful dairy management is maintenance of reproductive performance. In spite of the development of excellent synchronization and timed artificial insemination programs, conception rates in high milk producing herds remain low [1] [2] [3]. There are many potential breaches in the reproductive cycle where such failure can take place, from pre-ovulatory development through to aborted fetuses.

Walsh et al. [4] concluded that the most important causes for reproductive failure are negative energy balance in early lactation, poor detection of estrus, failure to produce high quality oocytes, and lack of sufficient progesterone production after fertilization. Other than estrus detection, these events can be mitigated to some extent and managed with nutritional support. For example, it is now better understood that the extent of and the duration of negative energy balance in early lactation is correlated with the interval to first postpartum ovulation [5] and can be reduced with dry cow feeding programs that improve intake during early lactation [6]. Reducing negative energy balance would likewise be expected to impact the quality of developing oocytes [2].

Fatty acids have also been demonstrated to play a role in optimizing reproductive performance in dairy cows. Two fatty acids are currently considered to be essential: linoleic acid (C18:2 $\omega$-6) and linolenic acid (C18:3 $\omega-3)$. Linoleic acid can be used to synthesize other $\omega$ - 6 fatty acids, while linolenic acid (LA) can be used by tissues to synthesize other $\omega$-3 fatty acids. Shortly after calving, the uterus synthesizes prostaglandins from the F series from the $\omega-6$ fatty acid family. These inflammatory compounds support the regression of the corpus luteum, uterine involution and ovulation [7]. Lipid mediators originating from the $\omega-3$ on the other hand have been shown to reduce the effects of estrogen, and to promote the release of progesterone [8]. Furthermore, Omega 3 fatty acids have been shown to improve oocyte development [9].

The problem with supplementation of essential fatty acids to ruminants is two-fold. First, fatty acids undergo lipolysis and biohydrogenation in the rumen. As a result, very little unsaturated fatty acids are available for absorption. Second, unsaturated fatty acids are toxic to rumen microbes [10]. Doreau and Chilliard [11] showed that higher amounts of fish oil given to dairy cows ( $>300$ $\mathrm{ml}$ ) resulted in lower dry matter intakes and reduce total milk fat synthesis. 
Mattos et al. [12] reported a 26\% reduction in milk fat yield with $200 \mathrm{~g}$ of fish oil when compared to $200 \mathrm{~g} / \mathrm{d}$ of olive oil. Thus there is a need to supply essential fatty acids, but in a form that does not interfere with rumen production.

On-farm trials offer the opportunity to evaluate large numbers of animals, and to better gain a perspective in performance parameters that may be too variable to evaluate in typical academic herds. Furthermore, reproductive performance can only be analyzed in retrospect, and is therefore a lengthy process that is not conducive to study in short term experiments. In order to evaluate the efficacy of a rumen protected fish oil supplement, three on-farm field trials were conducted with large well managed dairy herds.

\section{Materials and Methods}

All animals participating in these studies were handled in accordance with guidelines outlined by FASS [13]. These experiments did not impose any stress to the animals, but rather utilized information from record keeping systems already in use.

Three trials were conducted to evaluate the inclusion of a high omega 3 fatty acid supplement upon the reproductive performance of dairy cows. The herds involved in the studies were selected on the basis of superior management and maintenance of records, and were monitored by the attending consulting nutritionists. All records were compiled by Dairy Herd Improvement Association (National DHIA, Verona WI USA). Studies 1 and 2 were conducted in the Mid-West Dairy Belt in the USA, and involved heifers only. In both trials, heat detection was assessed using the Select Detect ${ }^{\mathrm{TM}}$ heat detection system. In brief, as cows approach estrus, physical activity increases. Monitors attached to cows detect movement on a continuous basis, and transmit the information to base stations, when the information is analyzed and used to schedule artificial insemination [14]. Heifers were inseminated at the first heat past the 55 day voluntary waiting period. Study 3 was conducted in Central Florida, USA and involved multiparous cows. These cows were on a scheduled artificial insemination program (Ovsynch). Cows were allowed a 57 day voluntary waiting period prior to entry into the program. Cows were injected within one week past the voluntary waiting period with $2 \mathrm{cc}$ of commercially available gonadotropin releasing hormone, and followed by a $2 \mathrm{cc}$ injection of gonadotropin releasing hormone 48 hours later. Cows were artificially inseminated upon detected heat.

In all studies, cattle received a ration with $40 \mathrm{~g}$ of a rumen protected fish oil supplement (Salmate ${ }^{\circledR}$ The Ballard Group, Cincinnati Ohio) during the test periods. This supplement provided 4.25 gram of rumen protected omega 3 fatty

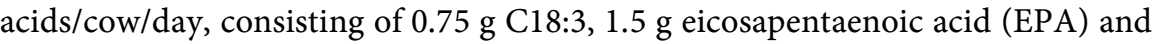
$2 \mathrm{~g}$ docosahexaenoic acid (DHA). The supplement was added to the grain portion of the total mixed ration prior to daily feed issue and was provided from the onset of lactation until $90 \pm 5$ days in milk. Cows entering the pen on or after the first day of the study were included in the dataset. Cows already in the pen at the 
start of the study were excluded from the analyses as they would not have received the supplement for the duration of the experimental period. Likewise cows that were less than 85 days in milk when the period of supplementation ended were excluded from the data analysis. Data from all animals that had received the supplement for the full feeding period were compared to records from the same time period the year prior. No supplement was provided during the control period, which in all trials occurred during the same season the year previous. For both groups of animals, records on all reproductive activity were followed for an 18 month period following the feeding portion of the study in order to capture accurate results for the number of times bred by treatment.

Statistical analyses were performed using Minitab 16 statistical software (Minitab, Inc., State College, PA, USA). The single mean analysis for number of services/cow was analyzed by ANOVA. The remaining parameters were analyzed using Fisher's Exact Test.

Definitions of the metrics analyzed are provided below:

Eligible breedings: Cows that are considered to be eligible for breeding if they are open and past the voluntary waiting period and have not been given a "do not breed" designation.

Heat observed (\%): heat observed is calculated as the number of cows bred as a percentage of the number calculated to be eligible.

Percent bred that became pregnant: This statistic is calculated after removal of any animals that were later determined to have an issue that prevented insemination.

Pregnancy rate (\%): This is defined as the percentage of cows eligible to become pregnant that actually do become pregnant after insemination.

Services/Conception: This is the number of inseminations required for successful pregnancy.

Abortions (\%): The percentage of cows that were either rebred or determined to be open after they were diagnosed to be pregnant. This value represents early term abortions.

\section{Results}

Results for the first primiparous study are given in Table 1. Although heat observed was lower $(P<0.05)$ during the test period than during the control period, the pregnancy rate was higher $(P<0.05)$ for the test supplemented group of cows, due to a greater percentage of cows diagnosed as pregnant. This is also reflected in the number of services/conception, which was greater during the control period $(P<0.05)$. There were no differences in early term abortions. The percentage was very low in this herd.

Similar results were found in the second trial, which also involved primiparous cows. In this case, there were no differences in heat observed. Again, the percent bred that became pregnant and pregnancy rates were improved with the addition of the rumen protected fish oil to the diet. There were no differences in 
Table 1. Results for primiparous cows given rumen protected fish oil supplement July through December 2012.

\begin{tabular}{cccc}
\hline & Control & Test & $P$ Value \\
\hline Animals eligible to be bred, \# & 1422 & 1235 & \\
Heat observed, \% & 66.2 & 61.4 & $<0.001$ \\
\% Bred that became pregnant & 20.6 & 30.8 & $<0.001$ \\
Pregnancy rate, \% & 14.8 & 22.4 & $<0.001$ \\
Services/conception & 5.48 & 2.89 & $<0.001$ \\
Abortions, \% & 1.23 & 0.82 & 0.066 \\
\hline
\end{tabular}

early term abortions that could be attributed to the treatment imposed $(P<0.05)$ (Table 2).

Results obtained when the supplement was provided to multiparous cows are shown in Table 3. In this herd, there were no differences in heat observed, the percent bred that became pregnant, pregnancy rate or services/conception. However, there was a reduction in the early term abortions for the period of time that cows received the supplementation.

\section{Discussion}

Large commercial dairy herds were used in these studies in order to obtain sufficient data to assess trends in reproductive performance from the use of the rumen protected fatty acid supplement. Herds were selected because the herd management maintained excellent records and took care to insure that correct quantities of the supplement were provided. The advantages of this type of study over an academic study include the fact that large numbers of cows are available for enrollment, and cows are not needed for subsequent experiments, and reproductive performances can be followed for extended period. There are some disadvantages. With the data comparing year over year, and it is possible to be influenced by environment (positively or negatively). Managerial changes, such as animals/pen or new equipment can also influence trial outcome. In these studies, the herds remained stable for both the control and test periods. It is therefore possible to draw inferences from the data obtained in these three trials.

Trial 1 and trial 2 involved heifers only. The percentage of cows bred that became pregnant was higher in both studies when the fish oil supplement was provided prior to breeding. In contrast, there were no differences in this variable in Trial 3, where mature cows were tested. It is of interest to note that the percent bred that became pregnant were higher for the control treatment in Trial 3 than in Trials 1 and 2. It is possible that the opportunity to improve this parameter was greater for the cattle in Trials 1 and 2 and more limited in Trial 3.

In a summary of older studies Sreenan and Diskin [15], estimated early embryonic mortality ( 1 - 28 days) in inseminated cows to be between $25 \%-30 \%$ of all pregnancies, with late embryonic mortality (29- 42 days) at $5 \%-8 \%$. More 
Table 2. Results for primiparous given a rumen protected fish oil supplement from March through June, 2013.

\begin{tabular}{cccc}
\hline & Control & Test & $P$ Value \\
\hline Animals eligible to be bred, \# & 1083 & 1001 & \\
Heat observed, \% & 60.5 & 61.25 & 0.822 \\
\% Bred that became pregnant & 29.75 & 38.25 & $<0.001$ \\
Pregnancy rate, \% & 17.75 & 22 & 0.037 \\
Services/conception & 3.16 & 2.24 & 0.012 \\
Abortions, \% & 9.2 & 5.6 & 0.101 \\
\hline
\end{tabular}

Table 3. Results for mature cows given a rumen protected fish oil supplement from January through June 2011 to 2012.

\begin{tabular}{cccc}
\hline & Control & Test & $P$ Value \\
\hline Animals eligible to be bred, \# & 3357 & 3984 & \\
Heat observed, \% & 54.8 & 56.1 & 0.109 \\
\% Bred that became pregnant & 35.4 & 34.5 & 0.076 \\
Pregnancy rate, \% & 18.2 & 19.5 & 0.154 \\
Services/conception & 2.73 & 2.93 & 0.466 \\
Abortions, \% & 16.8 & 4.7 & $<0.001$ \\
\hline
\end{tabular}

recently, Chagas e Silva et al. [16] reported early embryonic mortality of 33\% $37 \%$, and late embryonic mortality of $11 \%-24 \%$. Early embryonic mortality was lower in these three trials than average, but the percentages were numerically lower in Trials 1 and 2 and statistically lower in trial 3 when the supplemental fish oil was provided.

Early embryonic mortality on average was higher in Trial 3 involving mature cows than in Trials 1 and 2 where only heifers were tested. Differences between cows and heifers might be expected. Sartori et al. [17] determined that embryo quality was much better for heifers than for mature cows. Romano et al. [18] studied 360 cows and 160 heifers and reported 16.4\% embryonic mortality in cows as compared to $8.8 \%$ in heifers. This may be due to the demands of lactation as Sartori et al. [17] also found differences between dry and lactating cows with respect to embryo quality.

There is a logical role for omega 3 fatty acids in embryo survival. According to Otto et al. [1] omega 3 fatty acids are key to embryo survival. There is ample evidence to show that maternal reproductive tissues reflect the fatty acid profile of the fats being absorbed. These dynamic tissues have the ability to change with the diet being offered. Silvestre et al. [19] demonstrated that the fatty acid profiles of uterine cotyledons and caruncles could be altered by the type of fat provided. Wonnacott et al. [20] found that granulosa cells contained higher concentrations of EPA and DHA when provided to ewes 6 weeks prior to ovarian stimulation. 
The n-3 poly unsaturated omega fatty acids are required for the synthesis of steroid hormones. Progesterone is essential to support embryo development and implantation [21]. In addition, longer chain omega 3 fatty acids from fish oil have been shown to counter the action of PGF2 alpha in the uterus [12]. It has been shown that cows that exhibit an early post-insemination increase in progesterone by uterine tissues have an improved chance of conserving their pregnancy [4].

Fish oil longer chain fatty acids DHA and EPA are generally considered more effective than linolenic acid in supporting pregnancy. Although these fatty acids are synthesized from linolenic acid, linolenic acid and linoleic acid compete for shared desaturase and elongase enzymes [22], which can limit the conversion of linolenic acid to DHA and EPA.

The extent of biohydrogenation of fatty acidsis unpredictable, but in general is extensive. Doreau and Chilliard [11] ruminally infused $300 \mathrm{~g}$ of fish oil in the rumen of cows, and recovered very little of the EPA and DHA in abomasal contents. Kairenius et al. [23] provided cows with $250 \mathrm{~g} / \mathrm{d}$ of fish oil, supplying 15.9 $\mathrm{g}$ of EPA and $10.9 \mathrm{~g}$ of DHA. However, only $1 \%$ of each was recovered in the abomasum. Similarly, Shinfield et al. [24] recovered from the abomasum only $2 \%$ of the $43.5 \mathrm{~g}$ of EPA and $27.7 \mathrm{~g}$ of DHA provide in a diet where $250 \mathrm{~g} / \mathrm{d}$ of fish oil was supplemented. In addition, Boeckaert et al. [25] determined that the presence of DHA in the media in vitro studies reduced the biohydrogenation of linoleic acid, which resulted in greater formation of biohydrogenation intermediates known to reduce milk fat synthesis in addition to increasing absorbable linoleic acid to compete with omega 3 fatty acids.

In spite of significant biohydrogenation, there has been response to added fish oil, suggesting that the small quantities that escape the rumen can be beneficial to the reproductive performance of cattle. While it is no longer economically practical to provide large amounts of fish oil to cattle, there are some examples. Mattos et al. [12] provided cows with $200 \mathrm{~g} /$ day of fish oil and determined that levels of PGF2a could be reduced. Silvestre [19] provided cows with $1.5 \%$ of the diet as calcium salts of fish oil. In that study, embryonic losses were reduced with the fish oil supplementation.

In these trials the amounts of rumen protected EPA and DHA provided were small. However, based on the assumption that $15 \%$ of the EPA and DHA would escape fermentation, these concentrations were calculated to provide sufficient amounts of EPA and DHA based on results from published accounts of improved reproductive performance when unprotected fish oil was supplied in the diet [26] [27] [28] [29]. The test product evaluated in these trials appeared to deliver sufficient quantities of DHA and EPA to promote improvements in reproductive parameters in these herds. The ability supply these fatty acids post-ruminally may have been the key to their use.

\section{Conclusion}

Even though amounts provided were small, diet augmentation with a rumen 
protected omega 3 fatty acid supplement prior to breeding was found to be of benefit to reproductive performance in dairy cows when problems exist. Such a supplement can improve the percentage of cattle bred that become pregnant in herds where this metric is low. Early term abortions can be lowered; particularly in herds where this is might be a problematic occurrence.

\section{Acknowledgements}

The authors would like to thank Dr. E. Evans for assistance with statistical analysis.

\section{Conflicts of Interest}

The authors declare no conflicts of interest regarding the publication of this paper.

\section{References}

[1] Otto, J.R., Freeman, M.J., Malau-Aduli, B.S., Nichols, P.D., Lane, P.A. and Malau-Aduli, A.E.O. (2014) Reproduction and Fertility Parameters of Dairy Cows Supplemented with Omega-3 Fatty Acid-Rich Canola Oil. Annual Research and Review in Biology, 4, 1611-1636. https://doi.org/10.9734/ARRB/2014/7689

[2] Garnsworthy, P.C., Fouladi-Nashta, A.A., Mann, G.E., Sinclair, K.D., and Webb, R. (2009) Effect of Dietary-Induced Changes in Plasma Insulin Concentrations during the Early Post Partum Period on Pregnancy Rate in Dairy Cows. Reproduction, 137, 759-768. https://doi.org/10.1530/REP-08-0488

[3] Butler, W.R. (2003). Energy Balance Relationships with Follicular Development, Ovulation and Fertility in Postpartum Dairy Cows. Livestock Production Science, 83, 211-218. https://doi.org/10.1016/S0301-6226(03)00112-X

[4] Walsh, S.W., Williams, E.J. and Evans, A.C.O. (2011) A Review of the Causes of Poor Fertility in High Milk Producing Dairy Cows. Animal Reproduction Science, 123, 127-138. https://doi.org/10.1016/j.anireprosci.2010.12.001

[5] Butler, W.R. (2005) Nutrition, Negative Energy Balance and Fertility in the Postpartum Dairy Cow. Cattle Practice, 13, 13-18.

[6] Allen, M.S., Bradford, B.J. and Oba, M. (2009) Board-Invited Review: The Hepatic Oxidation Theory of the Control of Feed Intake and Its Application to Ruminants. Journal of Animal Science, 87, 3317-3334. https://doi.org/10.2527/jas.2009-1779

[7] Mattos, R.C. (2001) Nutritional and Pharmacological Strategies to Improve Conception Rates in Lactating Dairy Cows. Ph.D. Thesis. University of Florida, Gainsville.

[8] Bilby, T.R., Sozzi, A., Lopez, M.M., Silvestre, F.T., Ealy, A.D., Staples, C.R. and Thatcher, W.W. (2006). Pregnancy, Bovine Somatotropin, and Dietary n-3 Fatty Acids in Lactating Dairy Cows: I. Ovarian, Conceptus, and Growth Hormone-Insulin-Like Growth Factor System Responses. Journal of Dairy Science, 89, 3360-3374. https://doi.org/10.3168/jds.S0022-0302(06)72373-6

[9] Moallem, U., Shafran, A., Zachut, M., Dekel, I., Portnick, Y. and Arieli, A. (2013) Dietary a-linolenic Acid from Flaxseed Oil Improved Folliculogenesis and IVF Performance in Dairy Cows, Similar to Eicosapentaenoic and Docosahexaenoic Acids from Fish Oil. Reproduction, 146, 603-614. https://doi.org/10.1530/REP-13-0244

[10] Maia, M.R., Chaudhary, L.C., Figueres, L. and Wallace, R.J. (2007) Metabolism of 
Polyunsaturated Fatty Acids and Their Toxicity to the Microflora of the Rumen. Antonie Van Leeuwenhoek, 91, 303-314. https://doi.org/10.1007/s10482-006-9118-2

[11] Doreau, M. and Chilliard, Y. (1997) Effects of Ruminal or Postruminal Fish Oil Supplementation on Intake and Digestion in Dairy Cows. Reproduction Nutrition Development, 37, 113-124. https://doi.org/10.1051/rnd:19970112

[12] Mattos, R., Staples, C.R., Arteche, A., Wiltbank, M.C., Diaz, F.J., Jenkins, T.C. and Thatcher, W.W. (2004) The Effects of Feeding Fish Oil on Uterine Secretion of PGF2 $\alpha$, Milk Composition, and Metabolic Status of Periparturient Holstein Cows. Journal of Dairy Science, 87, 921-932. https://doi.org/10.3168/jds.S0022-0302(04)73236-1

[13] FASS (2010) Guide for Care and Use of Agricultural Animals in Research and Teaching. 3rd Edition, Federation of Animal Science Societies, Champaign, IL.

[14] Stevenson, J.S., Hill, S.L., Nebel, R.L. and DeJarnette, J.M. (2014) Ovulation Timing and Conception Risk after Automated Activity Monitoring in Lactating Dairy Cows. Journal of Dairy Science, 97, 4296-4308. https://doi.org/10.3168/jds.2013-7873

[15] Sreenan, J.M. and Diskin, M.G. (1986) The Extent and Timing of Embryonic Mortality in the Cow. In: Embryonic Mortality in Farm Animals, Springer, Dordrecht, $1-11$.

[16] Chagas e Silva, J.C., Da Costa, L.L. and Silva, J.R. (2002) Plasma Progesterone Profiles and Factors Affecting Embryo-Fetal Mortality Following Embryo Transfer in Dairy Cattle. Theriogenology, 58, 51-59. https://doi.org/10.1016/S0093-691X(02)00906-8

[17] Sartori, R., Sartor-Bergfelt, R., Mertens, S.A., Guenther, J.N., Parrish, J.J. and Wiltbank, M.C. (2002) Fertilization and Early Embryonic Development in Heifers and Lactating Cows in Summer and Lactating and Dry Cows in Winter. Journal of Dairy Science, 85, 2803-2812. https://doi.org/10.3168/jds.S0022-0302(02)74367-1

[18] Romano, J.E., Thompson, J.A., Kraemer, D.C., Westhusin, M.E., Forrest, D.W. and Tomaszweski, M.A. (2007) Early Pregnancy Diagnosis by Palpation per Rectum: Influence on Embryo/Fetal Viability in Dairy Cattle. Theriogenology, 67, 486-493. https://doi.org/10.1016/j.theriogenology.2006.08.011

[19] Silvestre, F.T., Carvalho, T.S.M., Francisco, N., Santos, J.E.P., Staples, C.R., Jenkins, T.C. and Thatcher, W.W. (2011) Effects of Differential Supplementation of Fatty Acids during the Peripartum and Breeding Periods of Holstein Cows: I. Uterine and Metabolic Responses, Reproduction, and Lactation. Journal of Dairy Science, 94, 189-204. https://doi.org/10.3168/jds.2010-3370

[20] Wonnacott, K.E., Kwong, W.Y., Hughes, J., Salter, A.M., Lea, R.G., Garnsworthy, P.C. and Sinclair, K.D. (2010) Dietary Omega-3 and -6 Polyunsaturated Fatty Acids Affect the Composition and Development of Sheep Granulosa Cells, Oocytes and Embryos. Reproduction, 139, 57-69. https://doi.org/10.1530/REP-09-0219

[21] Butler, W.R. (2001) Nutritional Effects on Resumption of Ovarian Cyclicity and Conception Rate in Postpartum Dairy Cows. BSAP Occasional Publication, 26, 133-145.

[22] Palmquist, D.L. (2009) Omega-3 Fatty Acids in Metabolism, Health, and Nutrition and for Modified Animal Product Foods. The Professional Animal Scientist, 25, 207-249. https://doi.org/10.15232/S1080-7446(15)30713-0

[23] Kairenius, P., Toivonen, V. and Shingfield, K.J. (2011) Identification and Ruminal Outflow of Long-Chain Fatty Acid Biohydrogenation Intermediates in Cows Fed Diets Containing Fish Oil. Lipids, 46, 587-606. 
https://doi.org/10.1007/s11745-011-3561-1

[24] Shingfield, K.J., Ahvenjärvi, S., Toivonen, V., Ärölä, A., Nurmela, K.V.V., Huhtanen, P. and Griinari, J.M. (2003) Effect of Dietary Fish Oil on Biohydrogenation of Fatty Acids and Milk Fatty Acid Content in Cows. Animal Science, 77, 165-179.

[25] Boeckaert, C., Vlaeminck, B., Mestdagh, J. and Fievez, V. (2007) In Vitro Examination of DHA-Edible Micro Algae: 1. Effect on Rumen Lipolysis and Biohydrogenation of Linoleic and Linolenic Acids. Animal Feed Science and Technology, 136, 63-79. https://doi.org/10.1016/j.anifeedsci.2006.08.015

[26] Burke, J.M., Staples, C.R., Risco, C.A., De La Sota, R.L. and Thatcher, W.W. (1997) Effect of Ruminant Grade Menhaden Fish Meal on Reproductive and Productive Performance of Lactating Dairy Cows. Journal of Dairy Science, 80, 3386-3398. https://doi.org/10.3168/jds.S0022-0302(97)76314-8

[27] Mattos, R., Staples, C.R., Williams, J., Amorocho, A., McGuire, M.A. and Thatcher, W.W. (2002) Uterine, Ovarian, and Production Responses of Lactating Dairy Cows to Increasing Dietary Concentrations of Menhaden Fish Meal. Journal of Dairy Science, 85, 755-764. https://doi.org/10.3168/jds.S0022-0302(02)74133-7

[28] Ballou, M.A., Gomes, R.C., Juchem, S.O. and DePeters, E.J. (2009) Effects of Dietary Supplemental Fish Oil during the Peripartum Period on Blood Metabolites and Hepatic Fatty Acid Compositions and Total Triacylglycerol Concentrations of Multiparous Holstein Cows. Journal of Dairy Science, 92, 657-669. https://doi.org/10.3168/jds.2008-1196

[29] Moussavi, A.H., Gilbert, R.O., Overton, T.R., Bauman, D.E. and Butler, W.R. (2007) Effects of Feeding Fish Meal and n-3 Fatty Acids on Ovarian and Uterine Responses in Early Lactating Dairy Cows. Journal of Dairy Science, 90, 145-154. https://doi.org/10.3168/jds.S0022-0302(07)72616-4 